Journal of Pragmatics 142 (2019) 47-61

https://doi.org/10.1016/j.pragma.2018.12.008

\title{
Signing something while meaning its opposite: the expression of irony in Italian Sign Language (LIS)
}

\begin{abstract}
When we utter something with the intention to communicate the opposite of what we are literally producing, assuming a mocking attitude towards our interlocutor, we are making use of irony. As far as we know, despite the vast literature on the status of irony markers (meta-communicative clues alerting the interlocutor that the utterance requires an ironic interpretation) in spoken languages, no research has been devoted at identifying irony markers in those languages that exploit the visual modality to convey meaning, i.e., sign languages. To start filling this gap, we administered to four Deaf native Italian Sign Language signers a Discourse Completion Task to obtain a semi-spontaneous elicitation of 10 minimal pairs of ironic/literal remarks expressing either compliments or criticisms. The analysis of this corpus revealed that: i) sentence meaning is expressed manually through the polarity of the evaluative lexical sign, ii) signer's attitude is expressed nonmanually through mouth-corners up and down, iii) ironic remarks show a prolonged articulation, and iv) irony might be further signaled by non-obligatory non-manual and manual cues.
\end{abstract}

\section{Keywords}

Italian Sign Language (LIS); Irony; Irony markers; Attitude; Non-manual markers

\section{Introduction}

"You did a great job!" is a sentence that can be used to praise or blame someone, depending on the communicative intention of the speaker. Its literal interpretation is couched on the very same meaning of the words, which transmit a positive message, and thus praise. When this sentence is used ironically, on the other hand, the speaker wants to convey a message that is the opposite of what she literally said: the positive evaluation is reversed and the remark is meant to convey a criticism. Even if ironic criticisms constitute the most common form of irony (Dews et al.,1995, cited in Dews and Winner, 1997), it is also possible to use a literally negative statement to convey a praise, as someone commenting "What a terrible cake you cooked!" after having devoured eight slices of it. Irony is thus a complex phenomenon that requires the detection of what the speaker intends to communicate - which is typically, even if not always, the opposite of what she said -, and also the recognition of the speaker's mocking attitude, which, at least in the case of verbal irony directed against a target, crucially involves an evaluation (a.o. Grice, 1978; Attardo, 2000a; Kotthoff, 2003; Partington, 2007). 
Differently from other types of figurative language, ironic statements may have a plausible literal interpretation, which would lead to misunderstanding and communication failures. It is therefore imperative that the ironist be reasonably certain that her interlocutors are able to interpret her utterance correctly (Principle of inferability, Kreuz, 1996).

In order to do so, speakers may rely on irony markers, that is, meta-communicative clues that alert the addressee that the utterance requires an ironic interpretation (Attardo, 2000 b). These irony markers may be realized phonologically, via a particular intonational contour, the so-called ironic tone of voice (but see Bryant and Fox Tree, 2005 for a critique of this notion), slower rate of speaking, syllable lengthening, and exaggerated stress (see Attardo, 2000b and references therein), or by means of particular syntactic constructions (e.g., rhetorical questions and superlative constructions) and lexical elements (e.g., extreme adjectives and adverbs). Ironic statements may also be associated with corporal expressions and gestures, such as winks, smiles, and laughter (Gibbs, 2000; Bryant, 2011) especially after the end of the ironic utterance (gestural codas, González-Fuente et al., 2015), even if Attardo et al. (2003) claimed that the so-called blank face, i.e., the absence of any particular facial expression, often accompanies ironic utterances.

Our research focused on the expression of irony in Italian Sign Language (LIS), aiming at identifying irony markers in a language that exploits the visual modality to convey meaning. Sign languages are full-fledged natural languages that can be formally described at all levels of linguistic structure (phonology, morphology, and syntax). To our knowledge, there is no systematic investigation of irony markers in any sign language, thus our study on the expression of irony in LIS is the first attempt to investigate the expression of verbal irony in a sign language.

We concentrated on ironic remarks that involve an explicit evaluation: ironic criticisms (literally positive remarks conveying criticism) and ironic compliments (literally negative remarks conveying compliments). The main research questions that guided our study were: (i) are there cues distinguishing between ironic and literal remarks? and (ii) (if any) how do they interact with the expression of attitude?

The paper is organized as follows. In Section 2, we provide an overview of the use of nonmanual markers in sign languages, which notably play a crucial role at different levels of linguistic representation and transmit prosodic information. Section 3 illustrates how linguistic data were collected and annotated for this study. In Section 4, we focus on the comparison between literal and ironic remarks in LIS, presenting the quantitative and qualitative results obtained from our study. In Section 5, we outline an irony toolkit for LIS and discuss the contribution of non-manual markers to the expression of irony and attitude. Section 6 concludes the paper.

\section{The role of non-manual markers in LIS}

In the literature of verbal irony in spoken languages, considerable attention has been paid to intonational modulations and prosodic cues (a.o. Attardo et al., 2003; Bryant and Fox Tree, 2002, 2005). Many studies indicate non-manual markers (i.e., facial expressions, head and body movements, henceforth NMMs) as ideal candidates for an intonational 
analogue in sign languages (for a discussion see Sandler, 1999; Wilbur, 2000; Sandler and Lillo-Martin, 2006). Given their relevance for this study, a digression should be made to provide a brief overview of the role of these elements in sign languages.

Traditionally, depending on their nature and function, NMMs have been divided into two categories: linguistic and affective (for a discussion, see Herrmann and Pendzich, 2014 and Brentari et al., 2018). The former play an important role at different levels of sign language grammar, while the latter are used by both signers and speakers to express emotions such as surprise or anger. Although they are both produced in the visualgestural modality, linguistic and affective NMMs differ in three main respects: scope, timing, and facial muscles (Reilly et al., 1990). On the one hand, linguistic NMMs have a clear onset and offset, activate specific facial muscles, are grammar-driven, and their distribution is constrained by the manual signs they co-occur with. On the other hand, affective NMMs are gradual, inconstant in their onset and offset patterns, global (they do not isolate specific facial muscles), and are not time-aligned with specific manual signs. Focusing our attention on linguistic NMMs, two well-known observations from the literature are that: i) one single NMM may be used with different functions (for a discussion of nonmanual multifunctionality, see Herrmann and Steinbach, 2013), and ii) two or more NMMs may be combined simultaneously in a layered fashion (Wilbur, 2000; Pfau and Quer, 2010). In the grammar of sign languages, NMMs play an essential role in different domains: phonology, morphology, syntax, semantics, and prosody (for an overview, see Pfau and Quer, 2010). To illustrate them, in the remainder of this section we present some concrete examples taken from studies on LIS. ${ }^{1}$ Following common usage in the field of sign language research, relevant NMMs are indicated by a straight horizontal line above the gloss(es). ${ }^{2}$

In the lexicon of LIS, we find that in some signs NMMs represent an obligatory component. For example, the articulation of the sign ASTONISHMENT requires raised eyebrows. The same manual sign accompanied with neutral eyebrows means "wake up" (Volterra, 2004:161). In other words, there are minimal pairs of signs that share the same manual parameters and differ in NMMs.

Single manual signs can be modified by NMMs fulfilling a morphological function. If the sign is a noun, the NMMs add an adjectival meaning to it. For example, protruding tongue combined with a noun usually expresses diminution, as shown in (1).

protruding-tongue

STREET

'narrow street' [adapted from Petitta et al., 2015:161]

\footnotetext{
1 Our goal here is not to provide the entire repertoire of NMMs in LIS, but rather some illustrative cases that can help the reader gain the background information relevant to the rest of the paper.

2 Glosses are words borrowed from spoken language used as identifying labels to refer to signs in a systematic way. Following standard practice in sign linguistics, glosses are written in small caps.
} 
If the sign is a verb, the superimposed NMMs add an adverbial meaning to it. In the example in (2) raised eyebrows, wide-open eyes, and open mouth (here labeled as 'pa') accompany the sign SEE and indicate that the action denoted by the verb occurs suddenly and unexpectedly.

(2) $\frac{\mathrm{pa}}{\mathrm{SEE}}$
'to suddenly see' [adapted from Volterra, 2004:165]

At the syntactic level, NMMs have a wide range of functions. They can mark several constructions: i) negative sentences (Geraci, 2006), ii) different sentence types (for polar interrogatives see Volterra, 2004; wh- interrogatives Branchini et al., 2013; imperatives Donati et al., 2017), iii) different types of embedded clauses (for relatives see Cecchetto, et al., 2006; for conditionals Barattieri, 2006; for comparative correlatives Geraci, 2007). As discussed in Wilbur (2000), NMMs can either mark a constituent boundary (edge markers) or spread across an entire syntactic domain (domain marker). To illustrate, we show in (3) an example of wh- interrogative in LIS: this construction requires a wh- sign in sentence-final position and the superimposition of furrowed brows. These NMMs must cooccur with the wh- sign and can optionally spread over the preceding signs (Branchini et al., 2013).

$$
\text { furrowed-brows }
$$

GIRL KISS WHO

'Who kisses the girl?' [adapted from Branchini et al., 2013:46]

Given their distribution, wh- NMMs can be considered domain markers. Moreover, NMMs play an important role in the encoding of focus, topic, and agreement (for an overview, see Bertone, 2011).

A number of recent studies have shown that NMMs are also used to express semantic constructions and convey nuances in meaning (for role shift see Zucchi, 2004; for definiteness Author, 2017; for low referentiality Author et al., in press).

To our knowledge, no systematic investigation has examined the function of NMMs in LIS on a pragmatic level. In Section 4.3, we investigate the pragmatic contribution of NMMs when used in evaluative statements.

\section{Methods}

The linguistic data used in this study were elicited data and acceptability judgments. This section provides details on the materials and task used to elicit the data (Section 3.1), the informants who participated in the data collection (Section 3.2), and the annotation procedure (Section 3.3).

\subsection{Materials and Irony task}


Our aim was to compare minimal pairs of remarks, namely compliments and criticisms produced both with a literal and ironic interpretation. To elicit these data, we first asked a native LIS signer to produce 10 pairs of discourse contexts in front of a camera. Each pair of contexts included two short stories that were identical except for the ending: one had a positive ending, the other a negative ending. One of the pairs of contexts recorded for this study is provided below, translated from LIS into English for illustrative purposes.

(4) Baseline: Alice and Chiara were born on the same day and decide to organize a birthday party together at Chiara's house. Chiara would like to organize it in the house, while Alice thinks that all their friends would find it boring to stay indoors, so she suggests organizing the party in the garden. Chiara insists and the party is organized indoors.

a. Positive ending: Chiara prepares nice decorations and suggests fun party games. All the children have a great time together!

b. Negative ending: however, at Chiara's house, there is nothing fun to do and all the children feel very bored.

In order to elicit the data, a Discourse Completion Task (Félix-Brasdefer, 2010) was designed. First, our informants (see Section 3.2) were asked to watch the pre-recorded context in LIS. Then, they were presented 2-4 glosses representing lexical items in random order (e.g., PARTY, FUN). One of these glosses was an evaluative sign providing either a positive or a negative assessment of the situation (e.g., BEAUTIFUL, HORRIBLE). Starting from these glosses, the informants were asked to complete the story producing a final remark.

The choice to use this type of task is based on two methodological motivations: i) the possibility to control situational variables and ii) the possibility to collect semi-spontaneous linguistic data. Explicit instructions such as "produce an ironic remark" would have led to unnatural outcomes.

\subsection{Informants and data collection}

Our data came from four Deaf LIS signers, two men and two women. They were all native users of the language since they were born to Deaf parents and have been exposed to LIS since birth. At the time of testing, our informants lived in Northern Italy, have had experience as LIS teachers, and were active members of the Deaf community. Before participating in the data collection, they all signed informed consent forms. With each informant, two elicitation sessions were held. To avoid memory bias, the two sessions were at least one month apart. In each session, 10 contexts were shown and the corresponding 10 final remarks were recorded with a professional digital video camera. Considering each pair of contexts (cf. Section 3.1), one version was presented in the first session, while the other in the second session. 
This elicitation design allowed us to collect for the same remark both the literal and ironic renditions. To illustrate, context (4) (above) triggered the final remark reported in (5), once with a literal and once with an ironic interpretation.

\section{PARTY FUN VERY}

'The party was really fun!'

From a procedural point of view, in one of the two sessions, we presented the informants with the context (4a) and then the glosses PARTY and FUN: this triggered the production of the literal version of (5). In the other session, context (4b) with the same two glosses triggered the production of the ironic counterpart.

During the first session, we were quite flexible on sign order and insertion of additional signs (other than the ones provided with the glosses, such as VERY in (5)) to let the informants sign in a way as natural as possible. These aspects were carefully controlled for during the second elicitation session in order to obtain minimal (or near-minimal) pairs of sentences.

Overall, for each informant, we recorded 20 sentences, i.e., 10 minimally-differing pairs, with each pair including the literal and ironic version of the same remark. Specifically, with 5 positive evaluative signs (e.g., BEAUTIFUL), we obtained 5 literal compliments (LiCo) and 5 ironic criticisms (IrCr). With 5 negative evaluative signs (e.g., WORTHLESS), we obtained 5 literal criticisms ( $\mathrm{LiCr}$ ) and 5 ironic compliments (IrCo). The minimal pairs collected for this study demonstrated that it is possible to express two different interpretations by using the same string of manual items. To illustrate, the glosses in (6) could be used to convey either literal compliment or ironic criticism, whereas those in (7) could be used to convey either literal criticism or ironic compliment.

(6) IX 3 BEAUTIFUL VERY

'That's very beautiful!'

(literal compliment \& ironic criticism)

HOUSE IX 3 WORTHLESS

'What an awful house!'

(literal criticism \& ironic compliment)

After the semi-spontaneous elicitation of the remarks in the Discourse Completion Task, informants were also involved in an Acceptability Task. On the basis of their own productions as well as other informants' productions, we asked them to evaluate the acceptability of the insertion of additional manual markers (cf. Section 4.2).

\subsection{Data annotation}

The 40 near-minimal pairs were annotated with two purposes: i) extract the duration in milliseconds of the whole remark and the evaluative lexical sign and ii) extract information about the presence and extension of special NMMs.

Each video-clip was named with an arbitrary code containing the ID letter of the informant (from ' $a$ ' to ' $d$ ') and a progressive number identifying the sentence: no reference was made to either remark type (literal vs. ironic) or signer's attitude (compliment vs. criticism). The 
clips were imported and annotated in ELAN (Crasborn and Sloetjes, 2008, version 4.9.4), an annotation software widely used in sign language linguistics. A representative screenshot is illustrated in Figure 1.

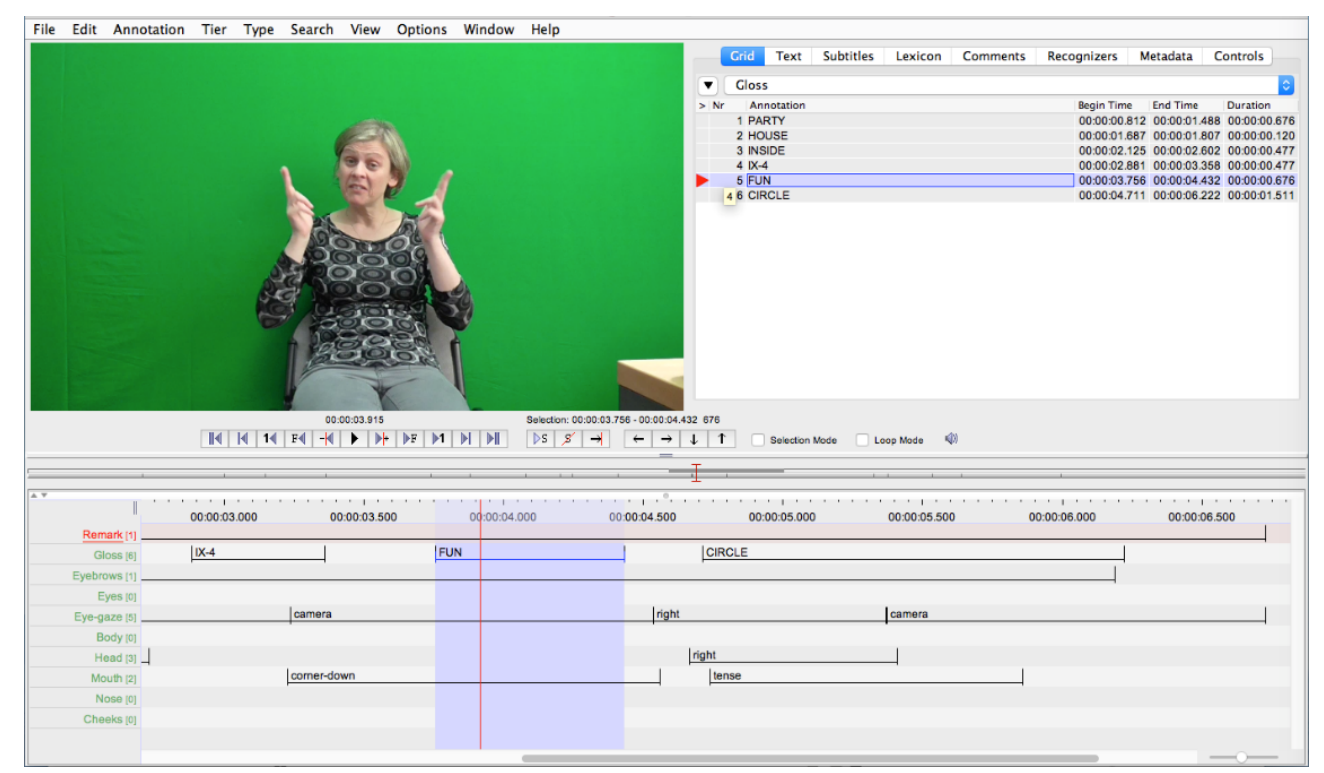

Figure 1: ELAN annotations

Data annotation was based on a coding schema containing 10 tiers, 2 for duration and 8 for NMMs. The list of tiers with the corresponding levels is provided in (8).

(8) a. Remark: the annotation served as indication of the full length of the remark;

b. Gloss: in this tier, each manual sign was associated with the corresponding gloss. The segmentation of the evaluative lexical sign served as an indication of its full length;

c. Body: shoulders up, forward lean, backward lean, left lean, right lean;

d. Head: single nod, multiple nods, lateral tilt, shake;

e. Eyebrows: up, down;

f. Eyes: closed, wide-open, squint;

g. Eye-gaze: camera, roleshift-addressee, up, down, left, right;

h. Nose: wrinkle;

i. Cheeks: puffed, tense;

j. Mouth: corners up, corners down, tense, open, visible teeth, visible tongue.

The segmentation for tiers (8)a and (8)b was performed by one coder only. As for NMMs, the simultaneous layering of different non-manual signals required careful scrutiny. To ensure coding accuracy, tiers from (8)c to (8)j were annotated by two independent coders. One coder was aware of both remark type and signer's attitude and annotated all the 80 remarks. The other performed a blind coding on 24 remarks (30\% of the corpus). The annotations of the two coders were compared with each other considering this subset of 24 remarks to test the inter-coder reliability. Agreement between the coders was evaluated over the presence/absence of 27 non-manual features. In the analysis, two non- 
manual articulators were discarded: Cheeks and Eye-gaze. The former was never present in the data, whereas the latter was consistently present in all the clips. As for Nose, agreement was perfect. As for the other tiers, we calculated the Cohen's Kappa. Between the two coders, there was substantial agreement (i.e., kappa between 0.61 and 0.80 ) considering all tiers (Eyes: $\mathrm{K}=0.80$, Eye-brows: $\mathrm{K}=0.70$, Mouth: $\mathrm{K}=0.73$, Head: $\mathrm{K}=0.66$, Body: $K=0.79$ ). Overall, this test confirmed that the annotations of the NMMs were reliable.

\section{Results}

To compare literal and ironic remarks in LIS, we investigated three aspects: i) duration of the evaluative lexical sign and whole remark, ii) manual markers, and iii) non-manual markers. We first present the findings we obtained from the quantitative analysis (Sections $4.1,4.2$, and 4.3 ), and then we complete the picture presenting some qualitative observations (Section 4.4).

\subsection{Duration}

We performed a quantitative analysis considering i) the duration of the whole remark ( $R$ dur), i.e., for each remark, the time that occurred between the beginning of the first sign and the end of the last sign (arms and hands in relaxed position) and ii) the duration of the evaluative lexical sign (Sign-dur).

Aggregate results are reported in Table 1 and Table 2. Table 1 compares the mean duration (in milliseconds) of the remark (R-dur) and of the evaluative sign (Sign-dur) across two conditions: remark type (literal vs. ironic remarks) and attitude (compliments vs. criticisms).

\begin{tabular}{|c|c|c|c|}
\hline & & R-dur & Sign-dur \\
\hline \multirow{2}{*}{ Remark type } & Literal & $4329(1644)$ & $630(283)$ \\
\cline { 2 - 4 } & Ironic & $5084(1397)$ & $654(337)$ \\
\hline \multirow{2}{*}{ Attitude } & Compliment & $4669(1524)$ & $667(310)$ \\
\cline { 2 - 4 } & Criticism & $4774(1620)$ & $617(311)$ \\
\hline
\end{tabular}

Table 1: Mean duration in $\mathrm{ms}$ and standard deviations

Table 2 considers literal compliments/criticisms and ironic compliments/criticisms separately. Notice that literal compliments/ironic criticisms (e.g., "That's very beautifu!!) and literal criticisms/ironic compliments (e.g., "What an awful house!") constitute minimal pairs.

\begin{tabular}{|c|c|c|c|c|}
\hline & Remark type & Attitude & R-dur & Sign-dur \\
\hline \multirow{2}{*}{$\begin{array}{c}\text { Minimal pairs } \\
\text { A }\end{array}$} & Literal & Compliment & $4439(1610)$ & $622(327)$ \\
\cline { 2 - 5 } & Ironic & Criticism & $5270(1368)$ & $596(373)$ \\
\hline \multirow{2}{*}{$\begin{array}{c}\text { Minimal pairs } \\
\text { B }\end{array}$} & Literal & Criticism & $4218(1713)$ & $638(240)$ \\
\cline { 2 - 5 } & Ironic & Compliment & $4899(1436)$ & $713(294)$ \\
\hline
\end{tabular}


The sign duration analysis showed no significant results. Here, we report Remark duration analysis only: R-dur analysis was conducted on 80 data points, 20 for each participant. We analyzed the data by means of linear models. As fixed factors, we entered the number of signs composing each remark (n_sign, we expected longer duration for remarks with a higher number of signs), remark type (literal vs. ironic), signer's attitude (compliments vs. criticisms) and their interaction. Notice that n_sign was balanced between literal and ironic remarks. We considered as dependent variable log(R-dur). The analysis revealed that the remark type by attitude interaction was not significant, and it was removed from the model without decreasing the model's goodness of fit $(F=2.69, p=.11)$. Attitude was not significant, and it was dropped from the analysis without decreasing the model's goodness of fit $(F=0.10, p=.76)$. The final model had two significant predictors: $n \_s i g n$ and remark type. R-dur increased as $n \_s i g n$ increased $(\beta=0.11, S E=0.02, t=5.08, p<.001)$ and ironic remarks were significantly longer than literal remarks $(\beta=0.15, S E=0.06, t=2.46, p=.02)$.

\subsection{Manual markers}

The elicitation of the 80 remarks revealed the spontaneous production of additional manual signs. The three most frequent items were PALM-UP, ARTICHOKE, and CIRCLE. ${ }^{3}$ Table 3 shows how they were articulated and how often they occurred in the different types of remarks collected in this study.

\begin{tabular}{|c|c|c|c|c|}
\hline \multirow{2}{*}{$\begin{array}{c}\text { Remark } \\
\text { type }\end{array}$} & \multirow[b]{2}{*}{ Attitude } & PALM-UP & ARTICHOKE & CIRCLE \\
\hline & & & & \\
\hline Literal & Compliment & $1 / 20$ & $0 / 20$ & $0 / 20$ \\
\hline \multirow{2}{*}{ Literal } & \multirow{2}{*}{ Criticism } & $7 / 20$ & $3 / 20$ & $1 / 20$ \\
\hline & & $35 \%$ & $15 \%$ & $5 \%$ \\
\hline \multirow{2}{*}{ Ironic } & \multirow{2}{*}{ Compliment } & $5 / 20$ & $5 / 20$ & $2 / 20$ \\
\hline & & $25 \%$ & $25 \%$ & $10 \%$ \\
\hline \multirow{2}{*}{ Ironic } & \multirow{2}{*}{ Criticism } & $2 / 20$ & $0 / 20$ & $6 / 20$ \\
\hline & & $10 \%$ & $0 \%$ & $30 \%$ \\
\hline
\end{tabular}

Table 3: Occurrences of additional signs in the elicited 80 remarks

\footnotetext{
3 PALM-UP is produced moving both upward oriented hands with a contralateral movement. ARTICHOKE is produced with one or two hands (flat closed 5 handshape) moving up and down. These labels are used in accordance with the existing literature (see EngbergPederson, 2002 and Branchini et al., 2013). To our knowledge, CIRCLE has never been investigated before: it is articulated with a $\mathrm{B}$ handshape rotating in a clockwise direction (for right-handed signers).
} 
The results reported in Table 3 show frequency data, i.e., how frequently signers produced PALM-UP, ARTICHOKE, and CIRCLE across the various conditions, in any position within the remark. Since all the elicited remarks contained an explicit evaluation, conveyed through an evaluative sign, we decided to focus our attention to the additional manual signs adjacent to the evaluative sign, and obtained the following picture:

\begin{tabular}{|c|c|c|c|c|}
\hline $\begin{array}{c}\text { Remark } \\
\text { type }\end{array}$ & Attitude & PALM-UP & ARTICHOKE & CIRCLE \\
\hline \multirow{2}{*}{ Literal } & Compliment & $0 / 20$ & $0 / 20$ & $0 / 20$ \\
& $0 \%$ & $0 \%$ & $0 \%$ \\
\hline \multirow{2}{*}{ Literal } & Criticism & $6 / 20$ & $3 / 20$ & $0 / 20$ \\
\hline \multirow{2}{*}{ Ironic } & Compliment & $30 \%$ & $15 \%$ & $0 \%$ \\
\hline \multirow{2}{*}{ Ironic } & Criticism & $20 \%$ & $4 / 20$ & $0 / 20$ \\
\hline
\end{tabular}

Table 4: Occurrences of additional signs adjacent to the evaluative sign

Taking into account only the signs produced immediately before or after the evaluative sign, the signs PALM-UP and ARTICHOKE were spontaneously produced only in literal criticisms and ironic compliments, whereas CIRCLE only appeared in ironic criticisms. To better understand the semantic contribution of these manual signs and collect crucial negative evidence, these manual signs were further investigated by eliciting acceptability judgments. Three informants out of four were explicitly asked to evaluate the acceptability of PALM-UP, ARTICHOKE, and CIRCLE across the various conditions and random contexts. The remarks judged as acceptable were recorded, while those judged as unacceptable were kept track of.

\begin{tabular}{|c|c|c|c|c|}
\hline Remark type & Attitude & PALM-UP & ARTICHOKE & CIRCLE \\
\hline Literal & Compliment & ${ }^{*}$ & ${ }^{*}$ & ${ }^{*}$ \\
\hline Literal & Criticism & $\checkmark$ & $\checkmark$ & ${ }^{2}$ \\
\hline Ironic & Compliment & $\checkmark$ & $\checkmark$ & $\checkmark$ \\
\hline Ironic & Criticism & ${ }^{*}$ & ${ }^{*}$ & $\checkmark$ \\
\hline
\end{tabular}

Table 5: Acceptability judgments on the manual signs PALM-UP, ARTICHOKE, and CIRCLE across the different remark types

Our informants confirmed what emerged from Table 4, that is, that PALM-UP and ARTICHOKE are acceptable in LiCr and IrCo only, as shown in (9) and (10), respectively.

(9) CONFUSION AS-BEFORE ARTICHOKE/PALM-UP [LiCr: b17] [LiCr: a22] 'It's a mess again!' (literal criticism)

(10) BOOK CONFUSION ARTICHOKE/PALM-UP [IICo: c41] [IrCo: d36] 'The books are all scattered around!' (ironic compliment) 
As these signs appeared both in literal and ironic remarks, they do not behave as irony markers. They tended to co-occur with signs expressing negative evaluation, like CONFUSION in (9) and (10). As previously mentioned, a literal criticism and an ironic compliment form a minimal pair because, despite the different interpretation, they superficially appear as negative remarks and share the same literal meaning. Therefore, the distribution of ARTICHOKE and PALM-UP suggest that they apply to the semantic dimension (i.e., negative evaluation).

On the other hand, CIRCLE behaved differently from the other two manual markers. Indeed, according to the intuitions of our informants, CIRCLE was judged as acceptable not only in ironic criticisms, as attested by Table 4, but also in ironic compliments. The examples in (11) and (12) show that CIRCLE is compatible both with a positive (e.g., BEAUTIFUL) and a negative (e.g., CONFUSION) evaluative sign, as long as the remark is ironic.

(11) PRESENT IX BEAUTIFUL CIRCLE [IrCr: C06]

'This present is so beautiful!'

(12) CONFUSION CIRCLE [IICo: d15]

'There's such a mess here!'

(ironic criticism, \# literal compliment)

(ironic compliment, \# literal criticism)

This empirical evidence supports the idea that CIRCLE is an irony marker.

\subsection{Non-manual markers}

In a preliminary observation, we checked the distribution of the NMMs across literal and ironic remarks, compliments and criticisms. For many NMMs we detected only few occurrences. Those NMMs that were counted in less than $20 \%$ of the remark (16 remarks) were not further considered. The distribution of NMMs across remarks is reported in Table 6.

\begin{tabular}{|c|c|c|c|c|c|}
\hline \multirow[b]{3}{*}{ Articulator } & \multirow[b]{3}{*}{ NMMs } & \multicolumn{4}{|c|}{ Type of remark } \\
\hline & & \multicolumn{2}{|l|}{ Literal } & \multicolumn{2}{|l|}{ Ironic } \\
\hline & & Compliments & Criticism & Compliments & Criticism \\
\hline \multirow{4}{*}{ HEAD } & Single nod & $\begin{array}{l}13 / 20 \\
65 \%\end{array}$ & $\begin{array}{l}7 / 20 \\
35 \%\end{array}$ & $\begin{array}{l}5 / 20 \\
25 \%\end{array}$ & $\begin{array}{l}11 / 20 \\
55 \%\end{array}$ \\
\hline & Multiple nods & $\begin{array}{l}8 / 20 \\
40 \%\end{array}$ & $\begin{array}{l}2 / 20 \\
10 \%\end{array}$ & $\begin{array}{l}10 / 20 \\
50 \%\end{array}$ & $\begin{array}{l}17 / 20 \\
85 \%\end{array}$ \\
\hline & Lateral tilt & $\begin{array}{l}11 / 20 \\
55 \% \\
\end{array}$ & $\begin{array}{l}8 / 20 \\
40 \%\end{array}$ & $\begin{array}{l}13 / 20 \\
65 \%\end{array}$ & $\begin{array}{l}14 / 20 \\
70 \%\end{array}$ \\
\hline & Shake & $\begin{array}{l}7 / 20 \\
70 \%\end{array}$ & $\begin{array}{l}9 / 20 \\
45 \%\end{array}$ & $\begin{array}{l}7 / 20 \\
35 \%\end{array}$ & $\begin{array}{l}2 / 20 \\
10 \%\end{array}$ \\
\hline \multirow{2}{*}{ MOUTH } & Corners up & $\begin{array}{l}13 / 20 \\
65 \%\end{array}$ & $\begin{array}{l}0 / 20 \\
0 \%\end{array}$ & $\begin{array}{l}14 / 20 \\
70 \%\end{array}$ & $\begin{array}{l}6 / 20 \\
30 \%\end{array}$ \\
\hline & Corners down & $\begin{array}{l}5 / 20 \\
25 \% \\
\end{array}$ & $\begin{array}{l}8 / 20 \\
40 \% \\
\end{array}$ & $\begin{array}{l}6 / 20 \\
30 \%\end{array}$ & $\begin{array}{l}14 / 20 \\
70 \%\end{array}$ \\
\hline
\end{tabular}




\begin{tabular}{|l|l|l|l|l|l|}
\hline \multirow{2}{*}{ EYES } & Wide & $5 / 20$ & $4 / 20$ & $7 / 20$ & $4 / 20$ \\
& & $25 \%$ & $20 \%$ & $35 \%$ & $20 \%$ \\
\cline { 2 - 6 } & Squint & $3 / 20$ & $10 / 20$ & $6 / 20$ & $5 / 20$ \\
& & $15 \%$ & $50 \%$ & $30 \%$ & $25 \%$ \\
\cline { 2 - 6 } & Closed & $11 / 20$ & $3 / 20$ & $2 / 20$ & $5 / 20$ \\
& & $55 \%$ & $15 \%$ & $10 \%$ & $25 \%$ \\
\hline EYEBROWS & Up & $11 / 20$ & $11 / 20$ & $13 / 20$ & $15 / 20$ \\
& & $55 \%$ & $55 \%$ & $65 \%$ & $75 \%$ \\
\hline
\end{tabular}

Table 6: Occurrences of NMMs across the different remarks

Up to now, we have simply reported the occurrences of NMMs within the whole remark. As discussed in Section 2, NMMs that have a linguistic (and not purely affective) function exhibit specific characteristics and, in particular, their distribution is constrained by the manual signs they co-occur with. We thus decided to conduct a more fine-grained analysis, counting how many of the NMMs we identified in the first analysis actually cooccurred with the evaluative sign. Results are reported in Table 7.

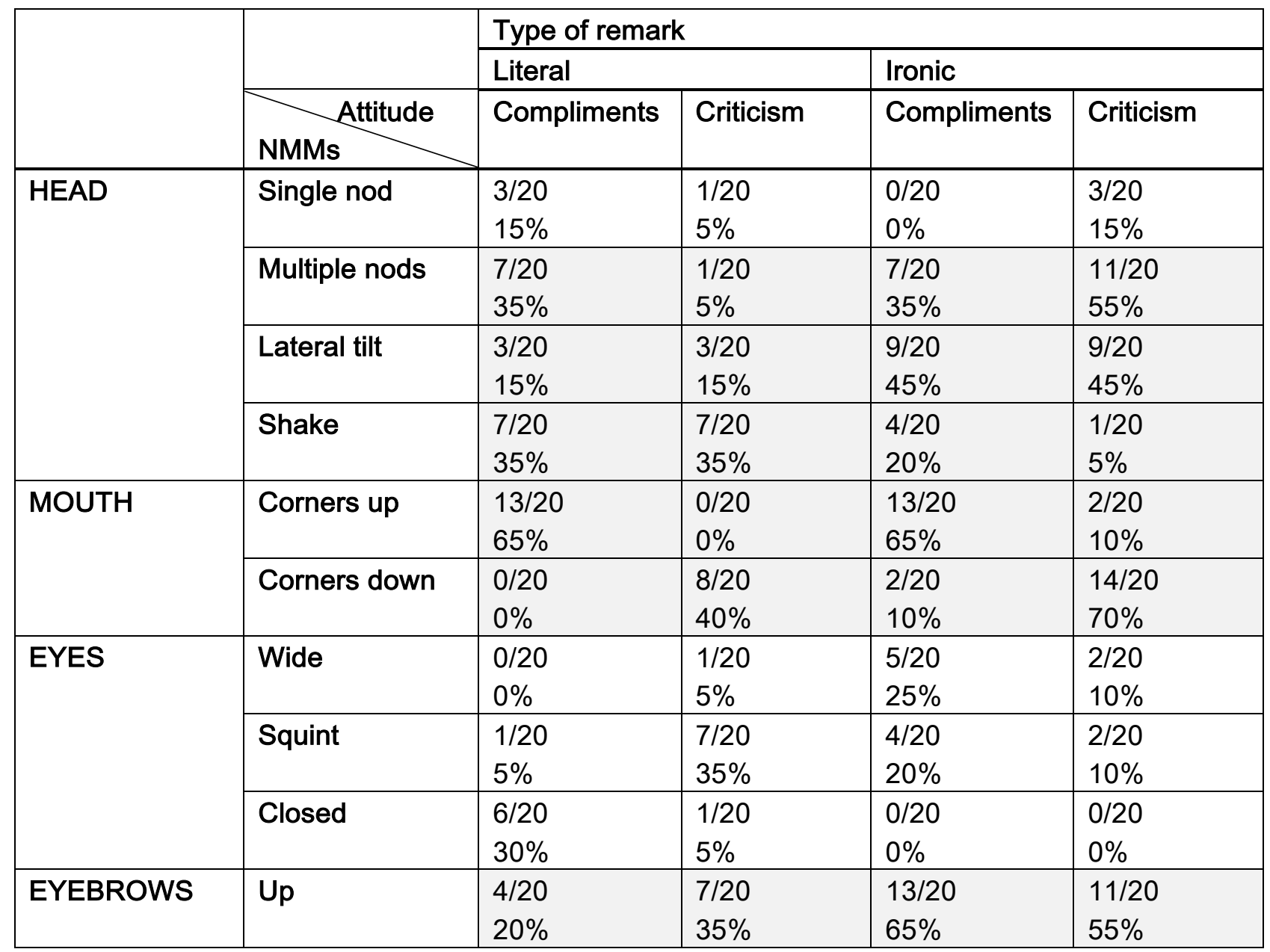

Table 7: Occurrences of NMMs co-occurring with the evaluative sign

Focusing on the NMMs co-occurring with the evaluative sign, we obtained a partially different picture from the one depicted in Table 6. As for the articulator Head, only few instances of single nods appear in correspondence of the evaluative sign (overall, only 7 
cases) and this suggests that the contribution of single nod might be informative of neither sentence meaning nor attitude. As for multiple nods and lateral tilts, we found many cases of these NMMs co-occurring with the evaluative sign. Multiple nods tended to appear in ironic statements ( 7 in $\mathrm{IrCo}$ and 11 in $\mathrm{IrCr}$ ), even if we found 7 instances of multiple nods in literal compliments. Considering lateral tilt, the attitude dimension was not informative, with a counting of 12 in both compliments (literal + ironic) and criticisms (literal + ironic). On the contrary, lateral tilts were present on $45 \%$ of evaluative signs contained in ironic remarks (i.e., $9+9$ lateral tilts out of $20+20$ evaluative signs on ironic remarks) and only $15 \%$ of evaluative signs contained in literal remarks (i.e., $3+3$ lateral tilts out of $20+20$ evaluative signs on literal remarks). We counted 19 occurrences of shake ( $24 \%$ of the total number of remarks), with a higher count for literal remarks (14), than for ironic remarks (5).

Considering Mouth, the distribution of corners up and corners down co-occurring with the evaluative sign confirms the pattern that emerged also from Table 6 . We found that mouthcorners up were almost only present on evaluative signs included in compliments (and specifically on $65 \%$ of those remarks), while mouth-corners down were almost only present on evaluative signs included in criticisms (and in 55\% of those remarks).

As for Eyes, their occurrence on the evaluative sign was very limited (wide: $10 \%$ of the total of 80 remarks; squint: $17.5 \%$; closed: $9 \%$ ).

Considering Eyebrows, we counted a total of 35 occurrences of raised brows (44\%), with only 11 occurrences on literal remarks (27.5\% of them) and 24 occurrences on ironic remarks $(60 \%$ of them).

To confirm these observations, we performed a statistical analysis considering those NMMs co-occurring with at least $20 \%$ (16) of the evaluative signs (highlighted in light grey in Table 7). The counts of each NMM on the evaluative sign in literal/ironic criticisms/compliments were analyzed by means of Poisson regressions. For each NMM, we entered as predictors remark type (ironic vs. literal) and attitude (compliments vs. criticisms). Considering Mouth, there was a significant effect of attitude on corners up, with less corners up in criticisms than in compliments $(\beta=-2.56, \mathrm{SE}=0.73, z=-3.49, p<.001)$ and a significant effect of attitude on corners down, with more corners down in criticisms than in compliments $(\beta=1.70, S E=0.54, z=3.14, p=.002)$. As for Eyebrows, remark type was a significant predictor of eyebrows up counting, with less eyebrows up in literal remarks compared to ironic remarks $(\beta=-0.78, S E=0.36, z=-2.14, p=.03)$. As for Head, the analysis on multiple nods revealed a significant remark type by attitude interaction: considering compliments, there was no difference between ironic and literal remarks, whereas ironic criticisms contained more multiple nods than literal criticisms. The analysis of lateral tilt and shake showed that remark type was significant, with less tilts in literal than ironic remarks and more shakes in literal than ironic remarks (tilts: $\beta=-1.09, S E=0.47, z=-2.33$, $p=.02$; shakes: $\beta=1.03, \mathrm{SE}=0.52, z=1.98, p<.05)$.

\subsection{Qualitative observations}

In the quantitative analyses presented in Sections 4.2 and 4.3, we followed a data-driven approach. Being aware of the limits imposed by our small corpus of data, we enriched our study with qualitative observations in an attempt to obtain a more accurate picture of the 
irony toolkit in LIS. In this section, our analysis was guided by a literature-driven approach: starting from the array of irony markers discussed in the existing literature, which is exclusively based on spoken languages, we examined our data to verify the presence of the same markers or equivalent markers behaving as analogues in the visual modality. At sentence level, previous studies showed that the ironic intent of the utterance may be signaled by tag questions (Kreuz, 1996), rhetorical questions (Barbe, 1995), focus topicalization (Seto, 1998), syntactic negation (Giora, Givoni, and Fein, 2015) and the use of negative elements at the end of the remark (e.g., 'not' in English, cf. Haiman, 1998), repetition and echo (Muecke, 1978).

Note that, in order to obtain minimal pairs of ironic/literal statements, our informants were provided with the glosses of the signs that had to be present in the remark, and were asked to stick to the exact forms presented as stimuli. This experimental bias might have limited the spontaneous production of particular items or constructions in ironic statements, and thus the few exceptions we report are even more enlightening. In the LIS data analyzed for this study, we observed that in some cases ironic remarks included tag questions, whereas the literal counterparts did not. This construction was spontaneously produced by two informants especially in ironic compliments. At the end of the remark, a personal pronoun indicating the interlocutor was produced. This tag was always accompanied by raised eyebrows (functioning as interrogative marker) and quick multiple head nods. This is illustrated in (13)b.

(13) a. DRAWING (IX) IX2 DONKEY ABSOLUTELY [LiCr: c69]

'You're rubbish at drawing!'

(literal criticism)

multiple-nods

raised-brows

b. DRAWING IX2 DONKEY IX $\quad$ [IRCO: D20]
IX

'You're rubbish at drawing, aren't you?' (ironic compliment)

The use of a negative element at the end of the remark was attested in our LIS data. It was realized as a head shake right after the last sign of the remark.

Focusing on the evaluative lexical element, it has been proposed that markers behaving as indicators of ironic intent are superlatives and intensifiers such as 'really' (Partington, 2007), hyperboles (Muecke, 1978), diminutives (Burgers et al., 2012), elongation of a vowel (Adams, 2012), and longer syllable duration (González-Fuente et al., 2015). As for superlatives, an informant produced the adjective BEAUTIFUL in a literal remark, and then he spontaneously produced the superlative form of this adjective in the ironic counterpart. Both remarks are shown in (14).

(14) a. IDEA (IX2) PROPOSE MOUNTAIN GO BEAUTIFUL [LiCo: C20]

'It was a good idea of yours to go to the mountains!' (literal compliment)

b. IDEA PROPOSE MOUNTAIN GO BEAUTIFUL-SUperl. [IrCr: c18]

'It was a great idea of yours to go to the mountains!' (ironic criticism) 
An analogue of hyperbole and elongation was found in several ironic remarks. It consisted in broadening the phonological movement of the evaluative sign in an exaggerated way. The examples in Figure 2 below show the same sign (FUN) with two different phonological realizations: neutral articulation when the interpretation is literal and exaggerated articulation when the interpretation is ironic.

(a)

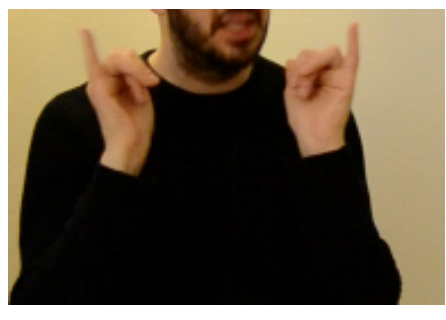

(b)

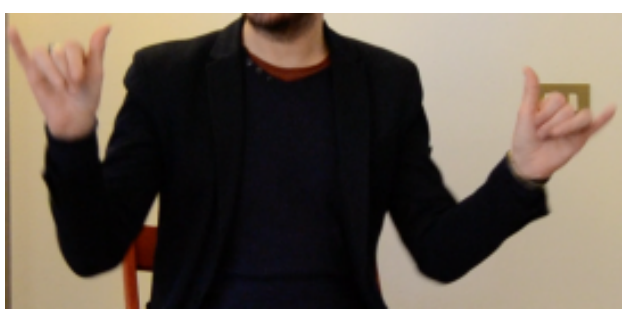

Figure 2: a) neutral phonological articulation [LiCo: c43]; b) exaggerated phonological articulation [IrCr: c47]

Such articulatory exaggeration is very likely to generate a prosodic elongation, similar to what has been previously found in spoken languages.

The paralinguistic features accompanying verbal irony have been extensively investigated in the literature. In particular, we would like to focus on two features for which we found analogues in our data: exaggerated pitch (Ackerman, 1983), emphatic tone nuclear configurations (González-Fuente et al., 2015), and extra-heavy expiration of air through the mouth (frequently realized as 'haha', 'hoho', 'heehee' in ironic remarks in English, cf. Haiman, 1998). The exaggerated pitch and emphatic tone nuclear configurations are similar to the wide-open eyes and raised eyebrows. The expiration of air is similar to a NMM observed at the beginning of some ironic remarks contained in our corpus. It consists in suddenly opening the mouth with an aspiration of voiceless stop ('haaa'). These NMMs are shown in Figure 3.

(a)

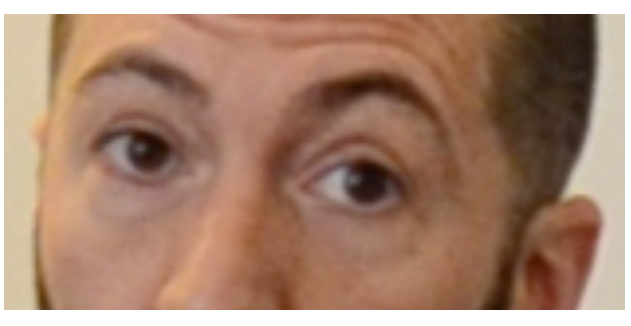

Figure 3: a) wide-open eyes and raised eyebrows [IrCr, c17];

\section{Discussion}

Our main research goal was to identify the cues distinguishing between ironic and literal remarks in LIS. The results emerging from the quantitative and qualitative analysis (Section 4) revealed an array of manual and non-manual markers that called for a deeper analysis. In Section 5.1 we discuss the strategies used to convey irony from a pragmatic perspective and in Section 5.2 we propose an account for the role of mouth patterns. 
These markers are intriguing since they were regularly distributed across the data, with a pattern tied to the expression of the signer's attitude, and not directly to the signer's (literal or ironic) meaning (cf. Section 4.3).

\subsection{The irony toolkit}

The results emerging from the quantitative and qualitative analysis allowed us to define a set of strategies that can be employed to make ironic remarks more easily detectable in LIS. We propose that these markers fulfill the function of alerting the audience of the nonliteral interpretation of the remark, and can then be grouped in three classes: warning, overemphasizing, and corrective strategies. Warning strategies signal to the interlocutor that she should pay attention to the interpretation of what was signed and hence are used to induce suspicion of irony. These cues include the prolonged articulation of the ironic remark with respect to its literal counterpart (cf. Section 4.1), and possibly sentence-initial open mouth, wide-open eyes and raised brows (cf. Section 4.4). Overemphasizing strategies serve to amplify the discrepancy between the literal content of what is signed and the actual situation and thus highlight one of the irony factors (Attardo, 2000a; Attardo et al., 2003): the incongruence between the remark and the situation. These overemphasizing markers include superlatives and exaggerated articulation (cf. Section 4.4), and might also include multiple nods, as it will be discussed at the end of this paragraph. Finally, corrective strategies make the ironic intent more easily detectable since they explicitly suggest reversal of evaluation (Partington, 2007). These cues include sentence-final head shakes, question tags, and the manual sign CIRCLE, since our informants judged it as not acceptable in literal remarks (cf. Section 4.2).

In the data collected for this study, we observed a layering distribution of warning, overemphasizing, and corrective strategies. As already mentioned in Section 2, the simultaneous combination of different markers is not a novelty in sign linguistics (Wilbur, 2000; Herrmann and Steinbach, 2013; Puupponen et al., 2015). With this respect, we argue that the more they overlap, the more evident and easily detectable the ironic interpretation becomes.

It should be noted that in our corpus these markers function as cues for verbal irony, but they can well be used in other linguistic domains in LIS with other functions. The fact that irony markers are not special to verbal irony has been observed in spoken languages as well (Attardo et al., 2003; Bryant, 2011; González-Fuente et al., 2015). To illustrate, we briefly discuss how two of the previously mentioned markers can be used in domains other than irony: prolonged articulation and multiple head nods. As for the increased duration, it has been noted that signers tend to slow down their signing rate to give special emphasis to a sign or an expression and mark linguistic prominence (Wilbur, 1999). Prolonged articulation has also been found at the final boundary of prosodic constituents, as an instance of phrase-final lengthening (for an effect of final lengthening in LIS wh-questions, see Branchini et al., 2013; for an effect of final lengthening in LIS nominal expressions, see Author, 2017).

As for multiple head nods, the analysis in Section 4.3 revealed that this NMM is used in many ironic remarks (18 occurrences), but it is also found in literal compliments ( 7 
occurrences). In the literature on LIS, head nods have been claimed to have an emphatic function, reinforcing the assertion, as in the example (15) discussed by Geraci (2006).

$$
\begin{aligned}
& \text { head-nods } \\
& \text { SOMEONE ARRIVE } \\
& \text { 'Someone did arrive.' }
\end{aligned}
$$

(emphatic reading)

The presence of multiple nods in literal compliments would then have the purpose of emphasizing the praise transmitted by the sincere remark. When multiple nods are used in ironic remarks, on the other hand, their function would be to overemphasize the assertion: this exaggeration highlights the incongruence with the context, and thus induce suspicion of irony.

\subsection{An account for the mouth patterns}

The analysis outlined in Section 4.3 revealed that mouth patterns conveyed signer's attitude: mouth-corners up compliment, whereas mouth-corners down criticism. This section is intended to discuss how these NMMs interact with the coding of irony. In order to account for them, we propose that irony in LIS can be inferred from the combination of sentence meaning and signer's attitude. As we will see, these two ingredients, the first manual and the second non-manual, systematically interact with each other, leading to a consistent and robust pattern. The first ingredient, sentence meaning, consists in the positive or negative evaluation expressed by the lexical evaluative sign (e.g., BEAUTIFUL and HORRIBLE). As for the second ingredient, signer's attitude, we claim that a key role is played by the position of the mouth. Henceforth, we refer to these NMMs with the term 'attitude NMMs'. The interaction between evaluative sign and position of the mouth indicates whether the sentence has to be interpreted literally or ironically. In principle, we expect the four patterns illustrated in Table 8.

\begin{tabular}{|c|c|c|}
\hline $\begin{array}{c}\text { Sentence } \\
\text { meaning }\end{array}$ & $\begin{array}{c}\text { Positive evaluative sign } \\
\text { (e.g., BEAUTIFUL) }\end{array}$ & $\begin{array}{c}\text { Negative evaluative sign } \\
\text { (e.g., HORRIBLE) }\end{array}$ \\
\hline $\begin{array}{c}\text { Moutth-corners up } \\
\text { (compliment) }\end{array}$ & $\begin{array}{c}\text { Match condition 1 } \\
\text { Interpretation: literal compliment }\end{array}$ & $\begin{array}{c}\text { Mismatch condition 2: } \\
\text { Interpretation: ironic compliment }\end{array}$ \\
\hline $\begin{array}{c}\text { Mouth-corners down } \\
\text { (criticism) }\end{array}$ & $\begin{array}{c}\text { Mismatch condition 1 } \\
\text { Interpretation: ironic criticism }\end{array}$ & $\begin{array}{c}\text { Match condition 2 } \\
\text { Interpretation: literal criticism }\end{array}$ \\
\hline
\end{tabular}

Table 8: Patterns emerging from the combination of sentence meaning and attitude

The qualitative analysis of our data provides empirical support in favor of this generalization. To illustrate, the screenshots below show concrete examples of how the interaction between evaluative sign and position of the mouth takes place. For the sake of clarity, Table 9 reports positive evaluative signs (BEAUTIFUL, BEAUTIFUL-superl., FUN) both in match and mismatch conditions, whereas Table 10 reports negative evaluative signs (CONFUSION, DIRTY, WORTHLESS, DONKEY) both in match and mismatch conditions. 


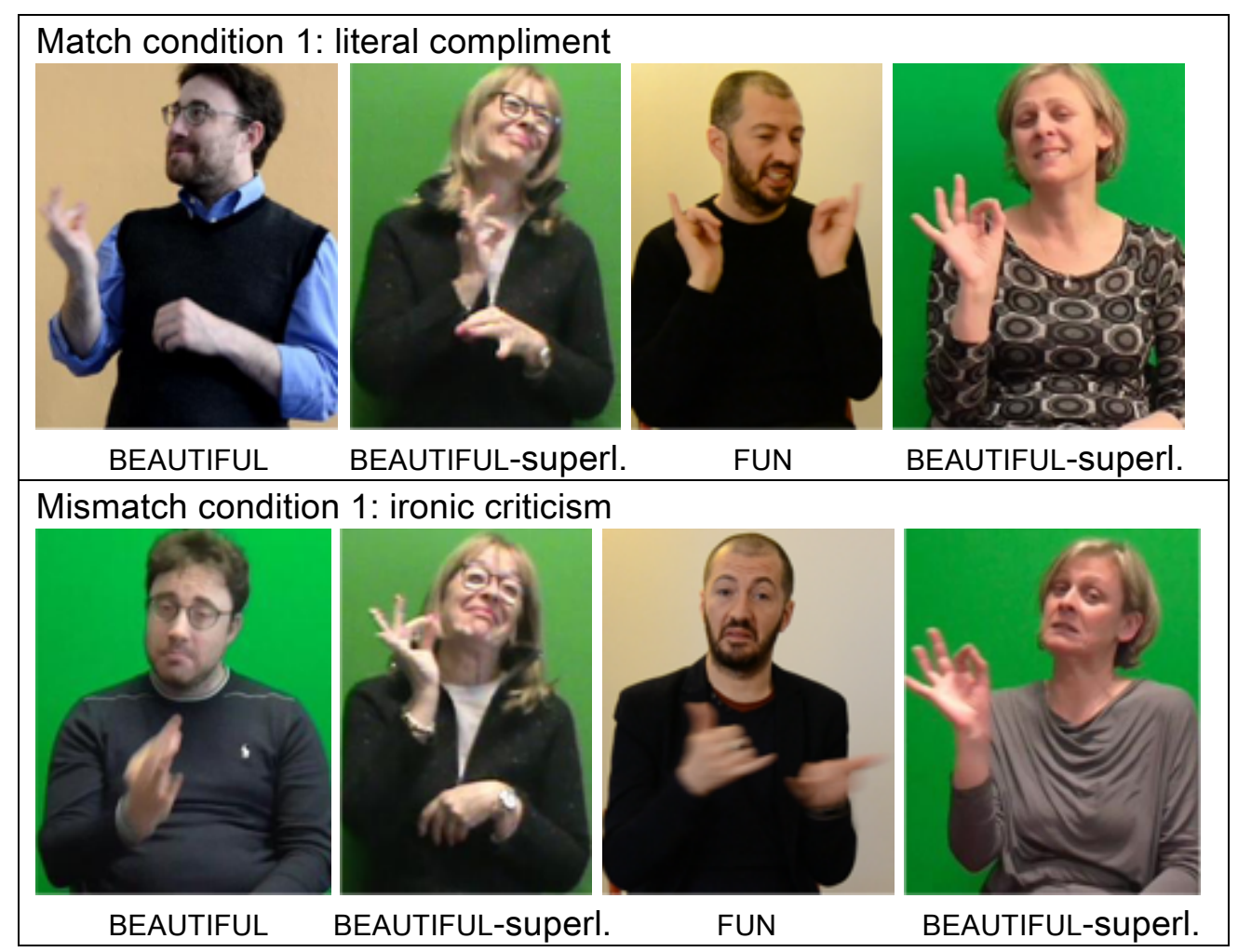

Table 9: Match and mismatch conditions with positive evaluative signs

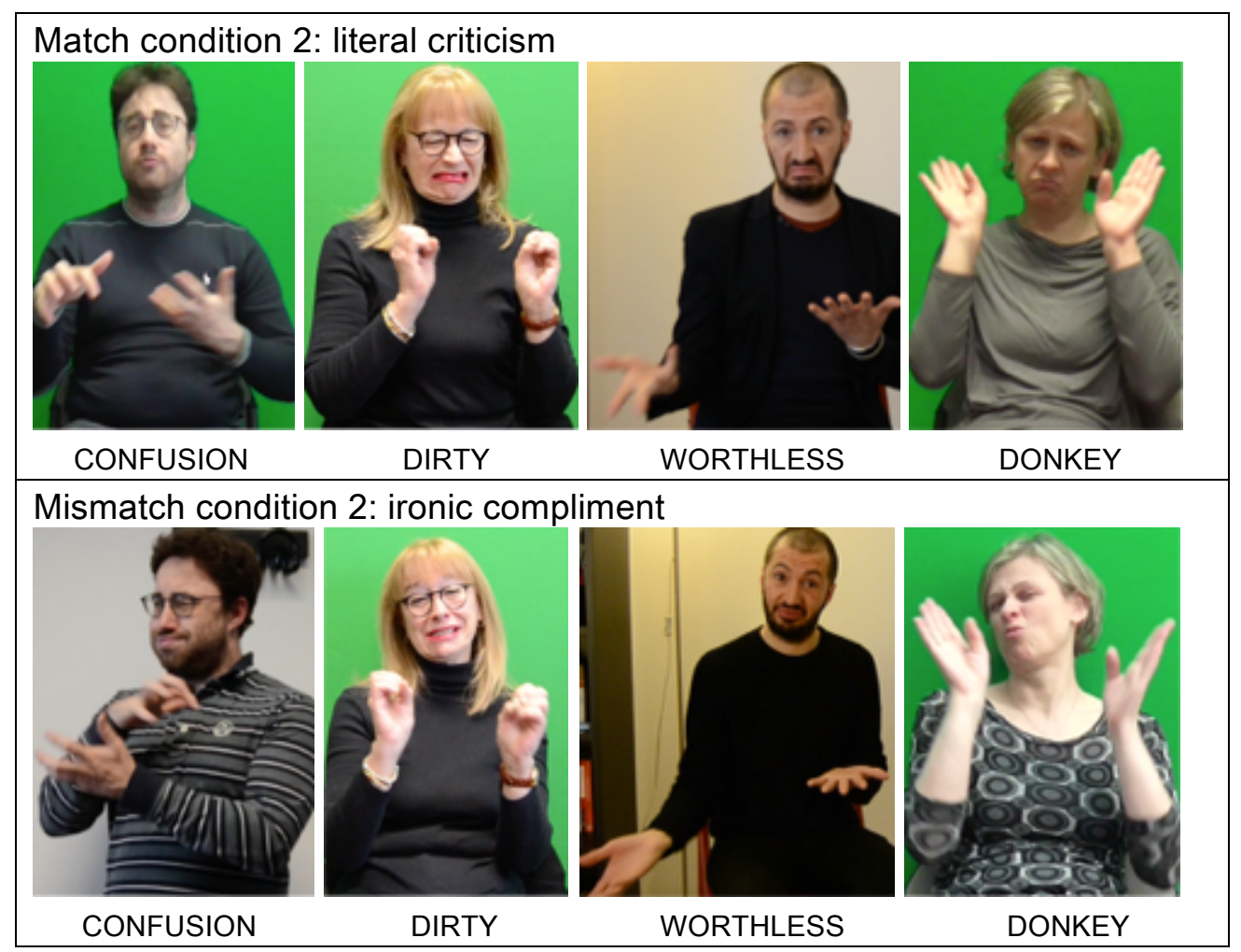

Table 10: Match and mismatch conditions with negative evaluative signs

Overall, these screenshots show that the abovementioned generalization systematically applies across evaluative signs and contexts in all our four informants.

The interaction between inherently negative sign and NMMs has also been discussed for Chinese Sign Language (CSL). According to Yang and Fischer (2002), if a negative sign in 
CSL is accompanied by a positive facial expression (here labeled as 'pfe') such as smiling the message is likely to be interpreted as sarcastic or insulting, or even ungrammatical. This is shown in the example in (16).

$$
\begin{aligned}
& \frac{\text { pfe (smile) }}{\text { ZHI (IX) HUA BUHAO }} \\
& \text { pointing draw no good } \quad \text { (Yang and Fischer 2002:174) }
\end{aligned}
$$

Unfortunately, the authors do not offer methodological details explaining how these judgments were collected. It would be interesting to know whether the combination between negative sign and positive facial expression is always judged by signers as unacceptable, or whether it could become acceptable given a context supporting an ironic interpretation (e.g., at first someone claims not to be a good drawer, and then she creates a wonderful drawing). As we saw in our LIS data, given an ironically biasing context, a negative evaluative sign combined with mouth-corners up produces an acceptable outcome interpreted as ironic compliment (mismatch condition 2, cf. Table 10). One last issue that needs to be discussed is the status of attitude NMMs. In particular, it would be informative to unravel whether they function as affective or linguistic NMMs. If they have a linguistic status, another interesting question is whether they apply to the evaluative sign only (at the lexical level) or to a larger domain (at the sentential level). The data at disposal do not allow us to come to any conclusive answer to that. However, there are some observations suggesting that attitude NMMs might be somehow integrated within the linguistic system. First, as shown in our analysis, mouth-corners up and down are systematically produced by all our informants to convey attitudinal meanings. Systematicity and absence of inter-signer variation are generally considered peculiarities of consistent linguistic patterns. Second, like functional linguistic elements, attitude NMMs constitute a closed class since the possible variables are only two (i.e., up and down). The closed status of this set of NMMs suggests that they are functional elements conveying abstract interpretive properties rather than descriptive content, and hence are part of the functional machinery of the language. Third, as systematic distribution has been claimed to be an important feature of linguistic NMMs (a.o. Brentari et al., 2018), we controlled for the distribution and extension of attitude NMMs within literal and ironic remarks. Closer scrutiny revealed that they can either concentrate on the evaluative sign or spread over the whole evaluative utterance. For illustrative purposes, these two options are exemplified in (17). ${ }^{4}$

$$
\text { _. - . - - corners-up }
$$

HAND IX DIRTY

'You have such dirty hands!'

(ironic compliment)

\footnotetext{
${ }^{4}$ A similar pattern is observed in another domain of LIS, wh- interrogatives, as we saw in example (3) above.
} 
Note that in both cases, as soon as attitude NMMs get activated, they are continuously produced until the end of their spreading domain. Like linguistic NMMs, they display clear onset and offset boundaries (cf. Section 2). Overall, attitude NMMs are not randomly distributed and seem to behave like domain-marking NMMs (cf. Section 2). We propose that, in order to express what the signer thinks about a particular judgment, they need to mark the domain of evaluation (i.e., the evaluative utterance) or, at least its nucleus (i.e., the evaluative sign, which defines the positive or negative polarity of the evaluation). The possibility for attitude NMMs to spread over an entire utterance suggests that they are endowed with a prosodic rather than lexical specification. ${ }^{5}$ Fourth, attitude NMMs convey specific semantic meanings that can be clearly recognized by other LIS signers. In a short follow-up experiment, we performed a comprehension task with three fluent signers on the remarks signed by one of our informants. We asked closed questions on signers' attitude (compliment vs. criticism) and all the participants attained ceiling performances.

To conclude, if our account is on the right track, mouth-corners up and down are linguistic tools used to convey a precise semantic information, the signer's attitude. Crucially, they interact with the evaluation expressed by the utterance and contribute to the coding of irony in LIS.

\section{Conclusions}

The starting point of this study was that one and the same string of manual signs in LIS can be used to convey two different interpretations: literal and ironic. These two readings are essentially computed from the relation between sentence meaning and signer's attitude. If these two dimensions are congruent (i.e., positive evaluation and compliment or negative evaluation and criticism) a literal reading is generated; if they are incongruent (i.e., positive evaluation and criticism or negative evaluation and compliment) an ironic reading is generated. Our study suggests that in LIS: i) sentence meaning is expressed manually through the polarity of the evaluative lexical sign, and ii) signer's attitude is expressed non-manually through mouth-corners up and down, which indicate the signer's communicative intention (i.e., compliment or criticism) and function as a pragmatic tool marking the domain of evaluation.

The analysis of our data showed that when producing ironic remarks, LIS signers resort to a number of manual and non-manual cues to guide the addressee toward the correct interpretation. The most frequent irony cues were prolonged articulation, multiple head nods, lateral head tilts, raised eyebrows, and the manual marker CIRCLE. Depending on the type, irony markers could be used to signal the non-literal interpretation (warning function), amplify the incongruence between sentence meaning and signers' attitude (overemphasizing function), and trigger evaluation reversal (corrective function). Our

\footnotetext{
${ }^{5}$ With this respect, attitude NMMs differ from the mouth patterns with evaluative function (diminution, augmentation, endearment, pejoration) discussed in Petitta et al. (2015), which typically combine with a single manual sign, be it lexical or classifier, instantiating a case of simultaneous morphology.
} 
analysis suggests that these markers are not special to verbal irony since they can be used in different domains as well. Another interesting finding is that these cues are not mutually exclusive, indeed they can combine simultaneously. As we proposed, this layering distribution contributes to creating a bigger bundle of information and making irony more noticeable.

A potential avenue for future research is to explore whether the use of these markers is influenced by the language and conversational habits of the hearing majority. This issue could be addressed by collecting data with Italian speakers through a similar semispontaneous task and comparing them with those collected with LIS signers. In particular, it would be interesting to draw a comparison between the manual and non-manual markers emerged from this study and the visual cues (e.g., facial expressions and cospeech gestures) employed by hearing Italian people. Are they the same in similar contexts? Do they occur in different contexts conveying different interpretations? This analysis would not only lead to interesting crosslinguistic and crossmodal considerations, but would also shed further light on the status of the markers investigated in this study. 


\section{References}

Ackerman, Brian P., 1983. Form and function in children's understanding of ironic utterances. Journal of Experimental Child Psychology 35 (3), 487-508.

Adams, Audrey Claire, 2012. Humor Markers in Computer-mediated Communication. MA thesis, Texas A\&M University-Commerce.

Attardo, Salvatore, 2000a. Irony as relevant inappropriateness. Journal of Pragmatics 32(6), 793-826.

Attardo, Salvatore, 2000b. Irony markers and functions: Towards a goal-oriented theory of irony and its processing. Rask 12 (1), 3-20.

Attardo, Salvatore, Eisterhold, Jodi, Hay, Jennifer, Poggi, Isabella, 2003. Multimodal markers of irony and sarcasm. Humor 16 (2), 243-260.

Author, 2017.

Author et al., in press.

Barattieri, Chiara, 2006. II Periodo Ipotetico nella Lingua dei Segni Italiana (LIS). MA Thesis, University of Siena.

Barbe, Katharina, 1995. Irony in Context. John Benjamins, Amsterdam.

Bertone, Carmela, 2011. Fondamenti di Grammatica della Lingua dei Segni Italiana. Franco Angeli, Milano.

Branchini, Chiara, Cardinaletti, Anna, Cecchetto, Carlo, Donati, Caterina, Geraci, Carlo, 2013. WH-duplication in Italian Sign Language (LIS). Sign Language \& Linguistics 16 (2), 157-188.

Brentari, Diane, Falk, Joshua, Giannakidou Anastasia, Herrmann, Annika, Volk, Elisabeth, Steinbach Markus, 2018. Production and Comprehension of Prosodic Markers in Sign Language Imperatives. Frontiers in Psychology 9, 770.

Bryant, Gregory A., 2011. Verbal irony in the wild. Pragmatics and Cognition 19 (2), 291309.

Bryant, Gregory A., Fox Tree, Jean E., 2002. Recognizing verbal irony in spontaneous speech. Metaphor and Symbol 17 (2), 99-117.

Bryant, Gregory A., Fox Tree, Jean E., 2005. Is there an ironic tone of voice? Language and Speech 48 (3), 257-277.

Burgers, Christian, van Mulken, Margot, Schellens, Peter Jan, 2012. Verbal irony: Differences in usage across written genres. Journal of Language and Social Psychology 31 (3), 290-310.

Cecchetto, Carlo, Geraci, Carlo, Zucchi, Alessandro, 2006. Strategies of relativization in Italian Sign Language. Natural Language \& Linguistic Theory 24 (4), 945-975.

Crasborn, Onno, Sloetjes, Han, 2008. Enhanced ELAN functionality for sign language corpora. In: Crasborn, O., Efthimiou, E., Hanke, T., Thoutenhoofd, E. D., Zwitserlood, I. (Eds.), Proceedings of the 3rd Workshop on the Representation and Processing of Sign Languages: Construction and Exploitation of Sign Language Corpora, 39-43.

Dews, Shelly, Winner, Ellen, Nicolaides, Natasha, Hunt, Malia, 1995. Forms and functions of verbal irony found in children's and adults' television shows. Paper presented at American Psychological Association, New York. 
Dews, Shelly, Winner, Ellen, 1997. Attributing meaning to deliberately false utterances: The case of irony. Advances in Psychology 122, 377-414.

Donati, Caterina, Barberà, Gemma, Branchini, Chiara, Cecchetto, Carlo, Geraci, Carlo, Quer, Josep, 2017. Searching for imperatives in European sign languages. In: Van Olmen, D., Heinold, S. (Eds.), Imperatives and Directive Strategies. John Benjamins, Amsterdam/Philadelphia, 184, 111-155.

Engberg-Pedersen, Elisabeth, 2002. Gestures in signing: the presentation gesture in Danish Sign Language. In: Schulmeister, R., Reinitzer, H. (Eds.), Progress in Sign Language Research: In Honor of Siegmund Prillwitz. Signum, Hamburg, 143-162.

Félix-Brasdefer, Julio C., 2010. Data collection methods in speech act performance: DCTs, role plays, and verbal reports. In: Martínez-Flor, A., Uso-Juan, E. (Eds.), Speech Act Performance: Theoretical, Empirical, and Methodological Issues. John Benjamins, Amsterdam/Philadelphia, 41-56.

Geraci, Carlo, 2006. Negation in LIS (Italian Sign Language). In: Bateman, L., Ussery, C.

(Eds.), Proceedings of NELS 35. GLSA, Amherst, MA, 217-229.

Geraci, Carlo, 2007. Comparative correlatives in Italian Sign Language. Traitement Automatique des Langues 48 (3), 55-92.

Gibbs, Raymond W., 2000. Irony in talk among friends. Metaphor and Symbol 15 (1-2), 527.

Giora, Rachel, Givoni, Shir, Fein, Ofer, 2015. Defaultness reigns: The case of sarcasm Metaphor and Symbol 30 (4), 290-313.

Gonzalez-Fuente, Santiago, Escandell-Vidal, Victoria, Prieto, Pilar, 2015. Gestural codas pave the way to the understanding of verbal irony. Journal of Pragmatics 90, 26-47.

Grice, H. Paul, 1978. Further notes on logic and conversation. In: Cole, P. (Ed.), Syntax and Semantics 9: Pragmatics. Academic Press, New York, vol. 9, 113-127.

Haiman, John. 1998. Talk is Cheap. Sarcasm, Alienation, and the Evolution of Language. Oxford University Press, Oxford.

Herrmann, Annika, Pendzich, Nina-Kristin, 2014. Nonmanual gestures in Sign Languages. In: Müller, C., Cienki, A., Fricke, E., Ladewig, S. H., McNeill, D., Bressem, J. (Eds.), Handbook Body - Language - Communication. De Gruyter Mouton, Berlin/Boston, 2149-2162.

Herrmann, Annika, Steinbach, Markus, (Eds.), 2013. Nonmanuals in Sign Languages. John Benjamins, Amsterdam/Philadelphia.

Kotthoff, Helga, 2003. Responding to irony in different contexts: On cognition in conversation. Journal of Pragmatics 35 (9), 1387-1411.

Kreuz, Roger J., 1996. The use of verbal irony: Cues and constraints. In Mio, J. S., Katz, A. N. (Eds.), Metaphor: Implications and Applications. Lawrence Erlbaum Associates, Mahwah, NJ, 23-38.

Muecke, Douglas C., 1978. Irony markers. Poetics 7, 363-375.

Partington, Alan, 2007. Irony and reversal of evaluation. Journal of Pragmatics 39 (9), 1547-1569.

Petitta, Giulia, Di Renzo, Alessio, Chiari, Isabella, 2015. Evaluative morphology in sign languages. In: Grandi, N., Körtvélyessy, L. (Eds.), The Edinburgh Handbook of Evaluative Morphology. Edinburgh University Press, Edinburgh, 155-169. 
Pfau, Roland, Quer, Josep, 2010. Nonmanuals: their prosodic and grammatical roles. In Brentari, D. (Ed.), Sign Languages. Cambridge University Press, Cambridge, 381402.

Puupponen, Anna, Wainio, Tuija, Burger, Birgitta, \& Jantunen, Tommi, 2015. Head movements in Finnish Sign Language on the basis of Motion Capture data: A study of the form and function of nods, nodding, head thrusts, and head pulls. Sign Language \& Linguistics, 18 (1), 41-89.

Reilly, Judy S., McIntire, Marina L., Bellugi, Ursula, 1990. Faces: The relationship between language and affect. In: Volterra, V., Erting J.C. (Eds.), From Gesture to Language in Hearing and Deaf Children. Springer-Verlag, Berlin, 128-141.

Sandler, Wendy, 1999. The medium and the message: Prosodic interpretation of linguistic content in Israeli Sign Language. Sign Language \& Linguistics 2 (2), 187-215.

Sandler, Wendy, Lillo-Martin, Diane, 2006. Sign Language and Linguistic Universals. Cambridge University Press, Cambridge.

Seto, Ken-ichi, 1998. On non-echoic irony. In Carston, R., Uchida, S. (Eds.), Relevance Theory: Applications and Implications. John Benjamins, Amsterdam, 239-255.

Volterra, Virginia (Ed.), 2004. La Lingua Italiana dei Segni. II Mulino, Bologna, 2nd edition. Wilbur, Ronnie B., 1999. Stress in ASL: Empirical evidence and linguistic issues. Language and Speech 42 (2-3), 229-250.

Wilbur, Ronnie B., 2000. Phonological and prosodic layering of nonmanuals in American Sign Language. In: Emmorey, K., Lane, H. (Eds.), The Signs of Language Revisited: Festschrift for Ursula Bellugi and Edward Klima. Lawrence Erlbaum, Mahwah, NJ, 213-244.

Yang, Jun Hui, Fischer, Susan, 2002. Expressing negation in Chinese Sign Language. Sign Language \& Linguistics 5 (2), 167-202.

Zucchi, Alessandro, 2004. Monsters in the visual mode? Unpublished manuscript, Università degli Studi di Milano. 